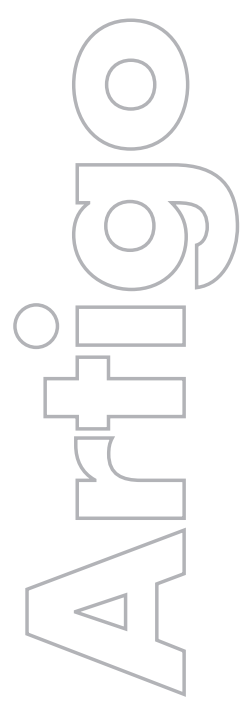

\title{
circuito rap indé em Paris: dinâmicas socioterritoriais e mensagem ultramar
}

Cristiano Nunes Alves

USP

p. $34-51$

\section{revista}

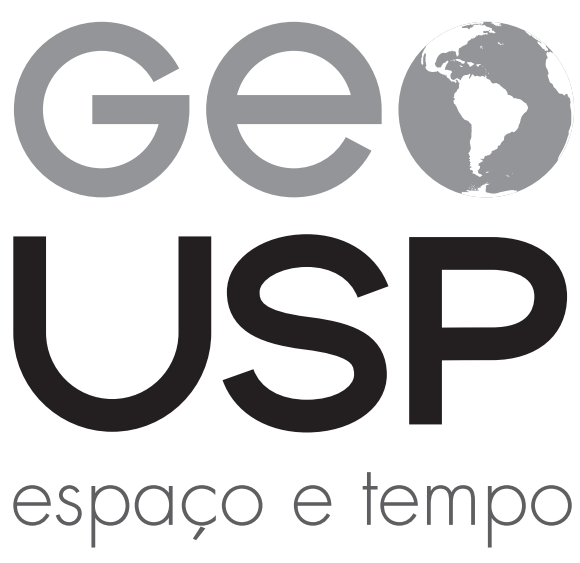

Volume $20 \bullet n^{\circ} 1(2016)$
Como citar:

ALVES, C. N. $\bigcirc$ circuito rap indé em Paris: dinâmicas socioterritoriais e mensagem ultramar. Geousp - Espaço e Tempo (Online), v. 20, n. 1, p. 34-51, mês. 2016. ISSN 21790892.

Disponível em: http://www.revistas.usp.br/geousp/article/ view/97502. DOI: http://dx.doi.org/10.11606/issn.2179-0892. geousp.2016.97502.

\section{(ㄷ) $(1)(9$}

Este artigo está licenciado sob a Creative Commons Attribution 4.0 License. 


\title{
circuito rap indé em Paris: dinâmicas socioterritoriais e mensagem ultramar
}

\section{Resumo}

Este artigo discute o circuito de rap independente em Paris, o chamado "rap indé", produção musical da cultura hip-hop constituída por materialidades e fluxos dinamizados por agentes cujas raízes estão em territórios ultramarinos. Por meio de um levantamento documental e bibliográfico e de uma série de entrevistas e visitas técnicas, problematiza-se a relação do hip-hop com o lugar e se analisa o rap indé a partir da teoria dos circuitos da economia urbana nos países do Terceiro Mundo. Observa-se que o circuito indé, fortalecido na Île-de-France, sobretudo desde meados dos anos 1990, mobiliza toda a região, tendo em Clignancourt um importante lugar de encontro e articulação. Produz-se em estúdios e selos de menor porte, caracterizando-se ainda por pequenas espessuras ligadas aos eventos musicais, e tem divulgação e comercialização alternativas aos grandes circuitos da economia. $\bigcirc$ estudo busca alternativas para analisar as dinâmicas socioterritoriais na cidade contemporânea a partir da música.

Palavras-chave: Rap indé. Paris. Dinâmicas socioterritoriais. Circuitos da economia urbana. Lugar.

\section{The indie rap circuit in Paris: socio-territorial dynamics and oversea message}

\begin{abstract}
We investigate the independent rap circuit in Paris, called the "indé rap" music production of hip-hop culture, consisting of materiality and flows dynamized by agents whose roots are in overseas territories. Drawing on a documentary and literature, and a series of interviews and visits, discusses to hip-hop relationship with the place, and proposes an analysis of indé rap from the theory of the circuits of the urban economy in third world countries. It is observed that the indé circuit, strengthened in the Île-de-France, especially since the mid-1990s, mobilizes the entire region, having in Clignancourt, important meeting place and networking. Its production occurs in studios and small labels, characterized by small thicknesses still linked to musical events, and dissemination and
\end{abstract}


marketing alternatives to large circuits of the economy. This is a study seeking alternatives to think about the ways of analyzing, from the music, the socioterritorial dynamics in the contemporary city.

Keywords: 'Indie' rap. Paris. Socio-territorial Dynamics. Urban Economics Circuits. Place.

\section{Introdução}

Manifestação artística essencialmente urbana, o rap, gênero musical da cultura hip-hop, ${ }^{1}$ chamada ainda de cultura das ruas, revela-se atualmente uma importante expressão de agentes segregados em todo o mundo. Considerada a música da persuasão e da tomada de consciência, o rap compõe-se de narrativas fundadas sobre rimas faladas, em geral, evocando a luta as populações periféricas citadinas. Os rappers se organizam para desenvolver sua arte a partir (1) dos grupos, constituídos pelo MC (mestre de cerimônias), e pelo DJ (Disc Jóquei), responsáveis, respectivamente, pelo canto e pela parte instrumental do rap e (2) das famílias, espécies de cooperativas reunindo certo número de grupos.

Na França o rap se espraia desde os anos 1980, sobretudo em metrópoles como Paris e Marselha, abrigo das produções pioneiras de Sidney, Dee Nasty, Assassin, IAM, entre outros (Puma, 1997; Guibert; Parent, 2004; Béru, 2009). Com o tempo, um vigoroso circuito de rap se adensa no hexágono (Grangeneuve, 2002; Hammou, 2008; Dubus, 2009; Guillard, 2012), tendo como especificidade em relação ao rap em outros países, sobretudo (1) um movimento dado basicamente por agentes de ascendência imigrante, oriundos de territórios ultramarinos e ex-colônias francesas (2) a combinação entre a modernidade intrínseca a produção do rap e as tradições do islã, religião praticada pela maior parte de seus militantes.

Fortalecido em Paris, notadamente desde meados dos anos 1990, hoje, o circuito rap se tornou importante variável do espaço geográfico, um conjunto inseparável de sistemas de objetos e sistemas de ações, criado pelo uso do território (Santos, 1997). Busca-se aqui analisar a espessura do circuito rap "independente" em Paris, o rap indé, assim denominado por seus agentes, dinamizado a revelia das grandes multinacionais do disco, entende-se, fecunda entrada para a reflexão sobre as dinâmicas socioterritoriais na cidade vista como mercado a partir da produção musical.

Em seu movimento, o circuito rap conforma e apropria-se de um sistema material, constituído por estúdios fonográficos, casas de shows, emissoras de rádio, lojas de discos e de artigos hip-hop em geral etc., além de mobilizar inúmeros objetos técnicos, desde equipamentos de produção fonográfica até cartazes de divulgação. Indissociado desse sistema material configura-se um sistema de ações, que compreende situações de encontro, constitutivas das associações e dos conflitos inerentes aos eventos musicais de rap, sessões de ensaio e gravação, oficinas e demais articulações, bem como todo o fluxo de informações do circuito rap, acionado por seus agentes, em músicas, palavras, atitudes, rimas e questionamentos.

\footnotetext{
1 Além do rap, a cultura hip-hop é composta pelo break (expressão corpórea) e pelo grafite (expressão visual). $\bigcirc$ break é um tipo de dança que se mistura a golpes de artes marciais, uma alternativa à luta entre gangues, que foram substituídas por combates de dança: as batalhas. Por sua vez, o grafite é um estilo de pintura presente nas mais diversas cidades, feito em muros, viadutos, vagões de trens, entre outros. Sua manifestação representa uma invasão simbólica dos agentes segregados que, por meio de imagens, transmitem suas mensagens para a urbe.
} 
Para o desenvolvimento da pesquisa, além do levantamento bibliográfico e documental sobre a temática, em livros, material cartográfico, artigos científicos, cartazes, discos, videoclipes, entre outros, foram fundamentais as informações primárias, obtidas em uma série de trabalhos de campo realizados em Paris e em cerca de oitenta comunas da região d' Île-de-France ao longo de 2012, durante estágio doutoral no Institut des Hautes Études de l'Amérique Latine (IHEAL), de Université Paris III.

Trata-se de informações primárias resultantes de visitas técnicas a locais conformados e/ou apropriados pelo circuito rap indé: estúdios fonográficos, órgãos do poder público, selos (pequenas gravadoras), lojas de discos, emissoras de rádios, casas de shows, entre outros e 23 entrevistas semiestruturadas, espécie de diálogos, junto a uma série de agentes ligados ao rap - rappers, produtores, articuladores, entre outros - abrigados em Paris e em doze comunas da região de Paris. ${ }^{2}$

Estrutura-se o presente artigo da seguinte maneira: primeiramente apresenta-se a problematização do tema, momento no qual se aborda a cultura hip-hop em sua ligação com o lugar, aventando-se a possibilidade de exame do rap indé a partir da reflexão sobre os circuitos da economia urbana nos países do Terceiro Mundo (Santos, 1979), uma vez tratando-se de uma produção movimentada por agentes ultramarinos.

Num segundo momento, oferece-se ao leitor a dinâmica em torno do lugar de encontro de grande parte dos agentes do circuito rap indé em Paris: Clignancourt, na saída norte da cidade. Em seguida, apresenta-se um panorama da produção fonográfica do circuito rap indé, enfocando-se os estúdios e selos acionados nesse sentido. Por fim, desenvolve-se o tema da circulação de informações no circuito indé, ocasião na qual se põe em relevo os eventos musicais, a difusão e a comercialização do rap na região de Paris.

O presente estudo faz parte de uma problemática mais ampla que temos desenvolvido, debruçando-nos sobre os circuitos musicais nas metrópoles brasileiras de Campinas e Recife. Com a proposta de analisar a repartição e a difusão das atividades sonoras e musicais no território, destaca-se, entre outros, os trabalhos de Gironcourt (1927), Carney (1974, 1990), Lévy (1999), Romagnan (2000), Claire (2006), Raibaud (2006) e Bettinelli (2007). Tais obras têm composto uma importante base analítica na busca pela compreensão da cidade atual a partir dos circuitos musicais.

\section{Em busca de uma problemática para o circuito rap indé: do lugar à análise dos circuitos da economia urbana no Terceiro Mundo}

Abordando-se por meio do circuito ${ }^{3}$ rap indé, a um só tempo a música e a dinâmica do território a partir da noção de circuito, busca-se melhor compreender a situação concreta resultante do processo de espacialização de normas, materialidades, ações e formas, que a partir dos usos mediados pela técnica, configuram o espaço geográfico e os seus lugares em Paris.

2 As informações decorrentes de entrevistas encontram-se ao longo do texto acompanhadas de um asterisco, indicando pesquisa em fontes primárias.

3 A noção de circuito espacial (Santos; Silveira, 2001) explica como se dinamizam as etapas da produção no espaço geográfico. Lançamos mão dessa ferramenta teórica para entender como funcionam as variáveis da produção musical e fonográfica e quais são suas repercussões espaciais: público, situação do encontro, serviços fonográficos, publicidade envolvida, formas alternativas de divulgação, custos etc. 
Santos (2006, p. 6) define o lugar como "o teatro das paixões humanas", esfera da proximidade e da contiguidade: abrigo de ações pautadas na rigidez, mas também constituídas de um conhecimento indisciplinado, comunicante, prenhe de espontaneidade e criatividade.

Uma das características essenciais da cultura hip-hop, atualmente uma linguagem mundializada, é sua relação com o lugar (Andrade, 1996; Keyes, 1996; Calogirou, 1996; Alves, 2005; Rérat, 2006; Gomes, 2012), esse espaço de "síntese" e "coabitação" (Moreira, 2007) consistindo, "em essência, num conceito do que é específico" (Hartshorne, 1978, p. 167).

Ao mesmo tempo a chamada "cultura das ruas" guarda um intenso caráter transterritorial amoldável a realidade dos mais diversos lugares do globo que the servem de abrigo (Alves, 2005; Gomes, 2012; Guillard, 2012), sinalizando para a associação e o conflito entre demandas culturais lugarizadas e mundializadas, dinamizadas por seus sujeitos políticos e por agentes da indústria cultural e demais poderes hegemônicos.

Por meio do circuito rap indé, particularmente questionador, alicerçado em ações cotidianas, observam-se manifestações da aspiração por um mundo diferente, menos desigual. Revelar-se-ia assim, a densidade comunicacional, mais radicada no lugar, no cotidiano, no saber e na produção de informações ascendentes (Santos, 1997, 2006), um elemento de transformação, pois portador de "interesses comuns que podem conduzir a uma consciência política" (Santos; Silveira, 2001, p. 101).

Ora, afirma-se entre os rappeurs indés que na França "são os filhos da África que fazem o rap", pois são eles os que têm algo a reivindicar, já que submetidos ao racismo e a discriminação de uma sociedade dividida. Daí apurar-se que, nesse circuito rap, agitado por agentes de origem ultramarina, grande parte jovens (Hammou, 2008) e moradores dos banlieues sensibles (Stébé, 1999; Giblin, 2009), predomina uma produção musical de cunho político, difundindo veemente a oposição ao Estado que, entre outros, tem combatido e censurado determinados grupos de rap, acusados de incitação à revolta.

Nessa via, os rappeurs indés abordam de modo recorrente fatos como o massacre de argelinos em Paris, perpetrado pelo governo francês em 17 de outubro de 1961; pelo que se observou, evento pouco discutido na sociedade francesa. Reconhecido pelo governo francês apenas em 2012, o massacre, ocasião em que dezenas de pessoas foram sumariamente executadas em virtude de uma manifestação pacífica pela independência da Argélia, auxilia no entendimento da fala de Zahef (Villiers-Le-Bel), rapper de ascendência argelina, traço do sentimento de boa parte dos agentes ultramarinos com relação ao Estado francês:

Nasci aqui na França, mas eu sou argelino, com certeza. Durante 100 anos, os franceses torturaram, estupraram e mataram nossos familiares... a maior parte das pessoas que estão aqui na sua frente não conhecem seus avós e hoje nós dizemos: foda-se a França, foda-se o governo.

Na mensagem do rap indé, defende-se o combate a agentes declaradamente racistas, como a Frente Nacional, partido francês de extrema direita; aborda-se igualmente temas, como os valores do islamismo, a vida nos banlieues, o pan-africanismo, a integração entre os povos do Terceiro Mundo, entre outros. 
Antes de se dizerem franceses, os rappeurs ultramarinos ${ }^{4}$ nascidos no hexágono afirmam as suas raízes no Terceiro Mundo, referindo-se a si próprios partindo delas: "os rappers vão dizer sem hesitar que não são franceses ainda que nascidos aqui na França”, explica o rapper de origem haitiana Atwoone (Créteil).

O circuito indé tem no rapper o trabalhador cultural realizador de todas as etapas da produção, investindo em si próprio, responsável, entre outros, pela criação, apresentação, divulgação, distribuição e comercialização de fonogramas, videoclipes, vestimentas e demais artigos ligados ao rap.

Para dar conta dessa multiplicidade de tarefas, o rapper, deve constituir em torno de si, densas redes de cooperação, mantendo a articulação com diversos outros agentes ligados à temática, como explica o rapper de origem argelina Moha (Kremlim Bicêtre): "É necessário trabalhar... fazer a parte instrumental da música, se inspirar, escrever, ir ao estúdio gravar, mixar... Tem a masterização, a capa, a prensagem. Depois deve-se distribuir o disco, encontrar boas redes, boas conexões".

Apurou-se que, malgrado a efervescente ação dos rappers parisienses "na verdade hoje pouca gente vive do rap", fato destacado por Attila (Sevran-Beaudottes), rapper de origem marroquina.

Os agentes ultramarinos do circuito rap indé entendem que o vínculo com uma grande empresa do disco significa a perda de autonomia, pois implica em compromissos com a indústria cultural, resultando, entre outros, na omissão de temas como o racismo ou a segregação urbana, configurando-se uma censura velada. Daí a crítica a artistas e grupos de rap franceses, tais quais Booba e Sexion d'Assaut, outrora tidos como militantes ultramarinos e agora considerados sem vitalidade em suas músicas, pois contratados por grandes gravadoras.

Dar-se-ia nesse contexto, o enfraquecimento da mensagem e da veracidade inerentes ao rap, gênero de canção pautado na narrativa do cotidiano, versando sobre aspectos inerentes ao espaço banal, o espaço de todos os agentes (Santos, 1997): "o rap é a nossa arma" afirmam os rappers do Selo/Familia Rott Chil (Sevran-Beaudottes) e, na mesma linha lembram os rappers do Selo Truand La Galère (Clignancourt): "Dizemos o que a gente quiser na música". Quase a totalidade dos rappers que compuseram o campo de informação primária em Paris, afiançou ser a independência uma postura opcional: "Nosso objetivo não é assinar com uma gravadora" relata um dos gerentes do Selo Ghetto Fabulous Gang (Clignancourt).

Caracterizado pela pulverização de objetos e ações por todo o banlieue parisiense, o circuito indé se constitui por incontáveis grupos e artistas de rap. Indício dessa vultosa espessura, averiguou-se em Fontenay Sur Bois, uma comuna de médio porte, a existência de cerca de 15 grupos de rap indé e dois estúdios fonográficos mais ligados a música da cultura hip-hop.

circuito indé é marcado ainda, pela pouca ou nenhuma relação com o circuito rap das grandes gravadoras: "Não tem nada a ver, são dois mundos paralelos" sentencia o agente do circuito rap Nans (Yvelines). Além de cindidos, esses dois circuitos - o circuito rap indé e o

4 Por sua vez, Zobda-Zebina (2009, p. 52) sugere a denominação EuroBlacks para os filhos da segunda geração de migrantes que dinamizam o rap na França hexagonal. 
circuito ligado às grandes gravadoras -, ao que tudo indica, dinamizam distintas espessuras: ao passo que é praticamente impossível apurar se o número de grupos indé abrigados na Île-de-France pode-se auferir a existência de aproximadamente uma dezena de grupos com gravadora na região.

Entre outros, o papel central do trabalho do agente ultramarino, a organização primitiva e personalizada, e a defesa de um discurso ascendente, demonstram o apreciável paralelismo e autonomia íntimos a dinâmica do circuito indé. Tais aspectos, tratados sob o prisma da economia política da cidade, conduzem a seguinte indagação: uma vez movimentado por agentes de origem ultramarina, em que medida o circuito indé poderia tornar Paris abrigo de práticas e materialidades, características do multifacetado Terceiro Mundo? Não se trata de uma simples transposição de práticas e materialidades do "sul do mundo" para um país "desenvolvido", mas sim parte de um processo de hibridização, corolário do período em curso.

Considerando essa possibilidade, evoca-se a proposta de abordar os circuitos da economia urbana no Terceiro Mundo segundo Santos (1979). $\bigcirc$ autor destaca que desde meados dos anos 1970 a informação e o consumo, duas variáveis elaboradas no centro do sistema mundo (Brunet; Dollfus, 1990) difundem-se nos países do Terceiro Mundo. Nessa reflexão, a dinâmica da urbe pautar-se-ia no movimento conjunto de circuitos superiores e inferiores da economia, ambos decorrentes de um incompleto processo de modernizações tecnológicas, sendo variáveis analíticas essenciais, o capital, a tecnologia e a organização envolvidos.

circuito superior teria como características o uso de um "capital intensivo" (Santos, 1979, p. 43), grandes volumes de mercadorias, ampla utilização de publicidade, se constituindo basicamente por bancos, comércios, serviços e indústrias modernas. Por sua vez, o circuito inferior, desdobramento indireto do processo de modernização territorial, pautar-se-ia no trabalho intensivo e lugarizado, no destacado potencial criativo, no trabalho com reduzidas quantidades, pouca ou nenhuma publicidade, áreas continuas de influência e serviços de pequena dimensão (Santos, 1979; Silveira, 2011).

Ainda que em sua proposta original a teoria dos circuitos da economia faça vir à tona a necessidade de se analisar a dinâmica socioterritorial do Terceiro Mundo; na afirmação de Santos (1979, p. 20), sobre a urgência de "saber se o comportamento do espaço é o mesmo em países desenvolvidos e em países subdesenvolvidos" repousa o interesse em verificar a existência de um circuito inferior da economia nos países do primeiro mundo no período atual.

Santos (1979, p. 72) a esse respeito, indaga-se sobre a possibilidade de "comparar as populações deserdadas das cidades dos países subdesenvolvidos com as massas pobres dos países desenvolvidos". O autor supracitado destaca alguns aspectos que fazem com que ele conclua que "mesmo se uma ou outra das características do circuito inferior pode ser reconhecida nas cidades dos países desenvolvidos, isso não é suficiente para se estabelecer uma comparação válida" (Santos, 1979, p. 74).

Propõe-se retomar os aspectos os quais Santos (1979) ressalta para balizar seu argumento, averiguando quais dessas feições ainda hoje permanecem em curso no centro do sistema mundo. 
Nesse sentido, o primeiro e basilar aspecto enfatizado por Santos (1979, p. 72) é o relativo pequeno número de pobres urbanos nos "nos países industriais". Ao que parece em tempos recentes a crise do capitalismo se espraiou atingindo com pujança alguns países do centro do sistema mundo, sendo este o caso francês. Dados do Instituto Nacional de Estatística e Estudos Econômicos da França (Insee) para o ano de 2012 indicavam que a pobreza no país atingia $13,9 \%$ da população, o que significa dizer que o hexágono abrigava cerca de 8,5 milhões de pessoas abaixo do limiar da pobreza. No mesmo ano, o Insee apontava 3,6 milhões de pessoas sobrevivendo em condições precárias de moradia ou sem-teto, estes eufemicamente chamados de "sem domicilio fixo (SDF)". ${ }^{5}$

Outro ponto citado por Santos (1979) é a limitada mobilidade do gueto no primeiro mundo. Acredita-se que hoje esse aspecto em larga medida se dissipou na capital francesa, algo demonstrado pelo simples exame da paisagem da metrópole parisiense, abrigo de uma grande espessura de bens e serviços destinados às classes mais populares, localizados, sobretudo na zona norte da capital e de sua região, coincidindo com o lugar de residência da maior parte dos pobres urbanos.

Um terceiro aspecto, que no período atual parece aproximar os países do Primeiro e do Terceiro Mundo, é o fato de o Estado de bem-estar social ter encolhido naqueles, diminuindo a "pobreza com segurança" (Santos, 1979, p. 74). Nesse ponto em especial soma-se o fato de na França ter-se configurado uma legião de "cidadãos de segunda classe", composta por coletivos como os ciganos, mas em sua maior parte pelos agentes ultramarinos, que entre outros, dinamizam o circuito rap indé.

Quais dos aspectos constituintes do circuito inferior da economia parecem desvelar-se por meio do exame da dinâmica do circuito rap indé de Paris? Tendo como fio condutor tal indagação, a seguir, procura-se, sistematizando a presente empiria, contribuir à discussão sobre os caminhos possíveis para a análise da cultura na cidade contemporânea, desigual e segregada.

\section{Em Clignancourt, o encontro e a articulação do circuito indé: cotidiano e círculos de cooperação no território}

No norte da cidade de Paris observou-se, grosso modo, desde Clichy até Belleville um maior fluxo de franceses de ascendência migrante, em especial provenientes das ex-colônias francesas e dos atuais departamentos de ultramar, bem como os bens e serviços que atendem essa parcela da população (restaurantes, cabeleireiros, vendedores ambulantes, entre outros).

Identificou-se no Marche Aux Puces, em Clignancourt, Saint-Ouen ao norte da cidade de Paris, a existência de um lugar de encontro para os agentes do circuito rap indé. Em "Clicli", como a área é chamada entre os rappers, a um só tempo, abriga-se um centro de comércio da produção fonográfica e de articulação do circuito rap indé (Figura 1, Fotos 1, 2 e 3).

5 Em um levantamento que fizemos em Paris em 2012 com o professor Lucas Manassi Panitz (Universidade Federal de Pelotas), pudemos atestar o alto número de sem-teto e moradores de aglomerados e habitações precárias, as chamadas bidonvilles, na região francillienne. 
Figura 1 - Glignancourt - localização

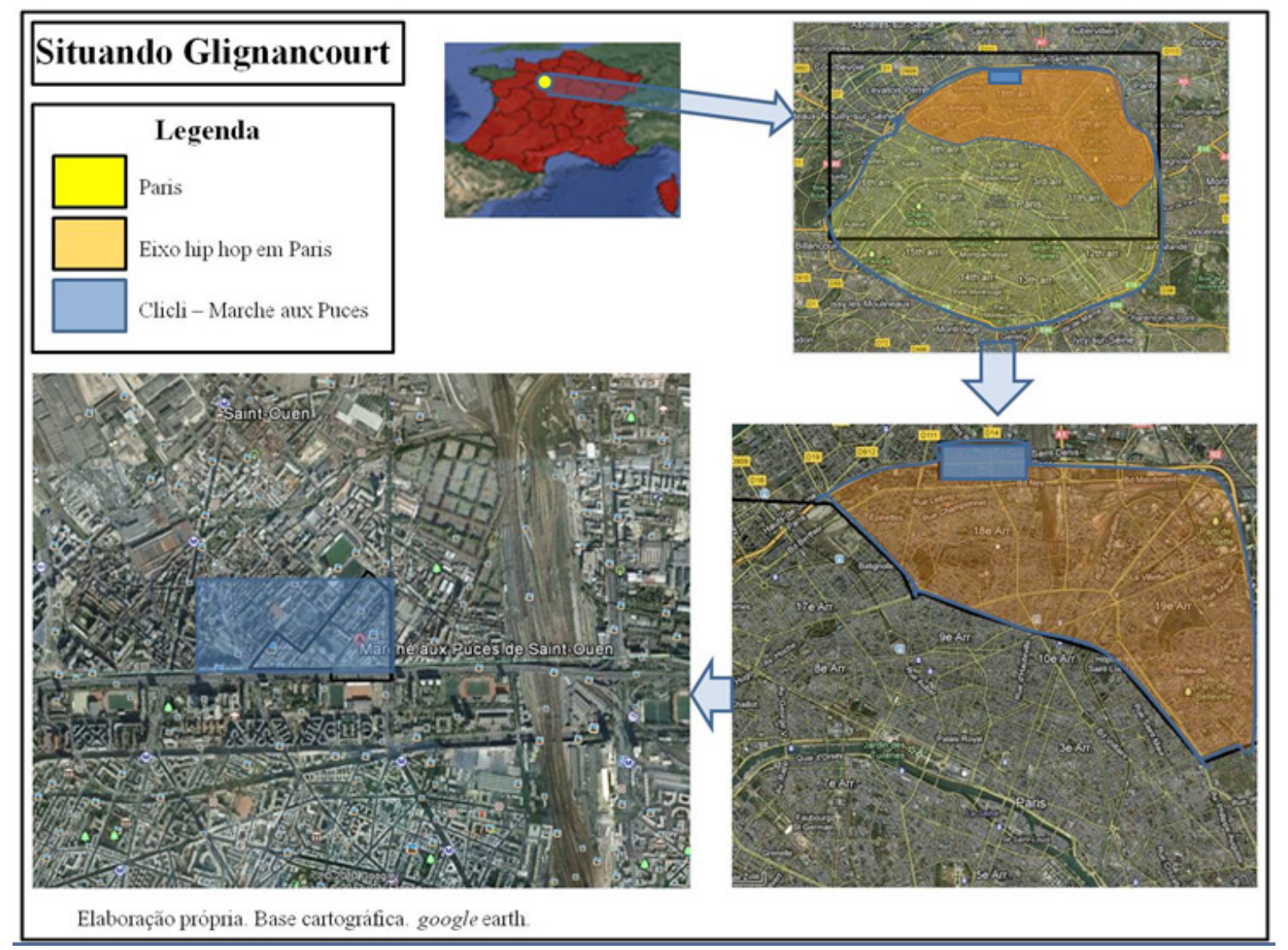

Fotos 1, 2 e 3 - Clignancourt e o circuito rap indé

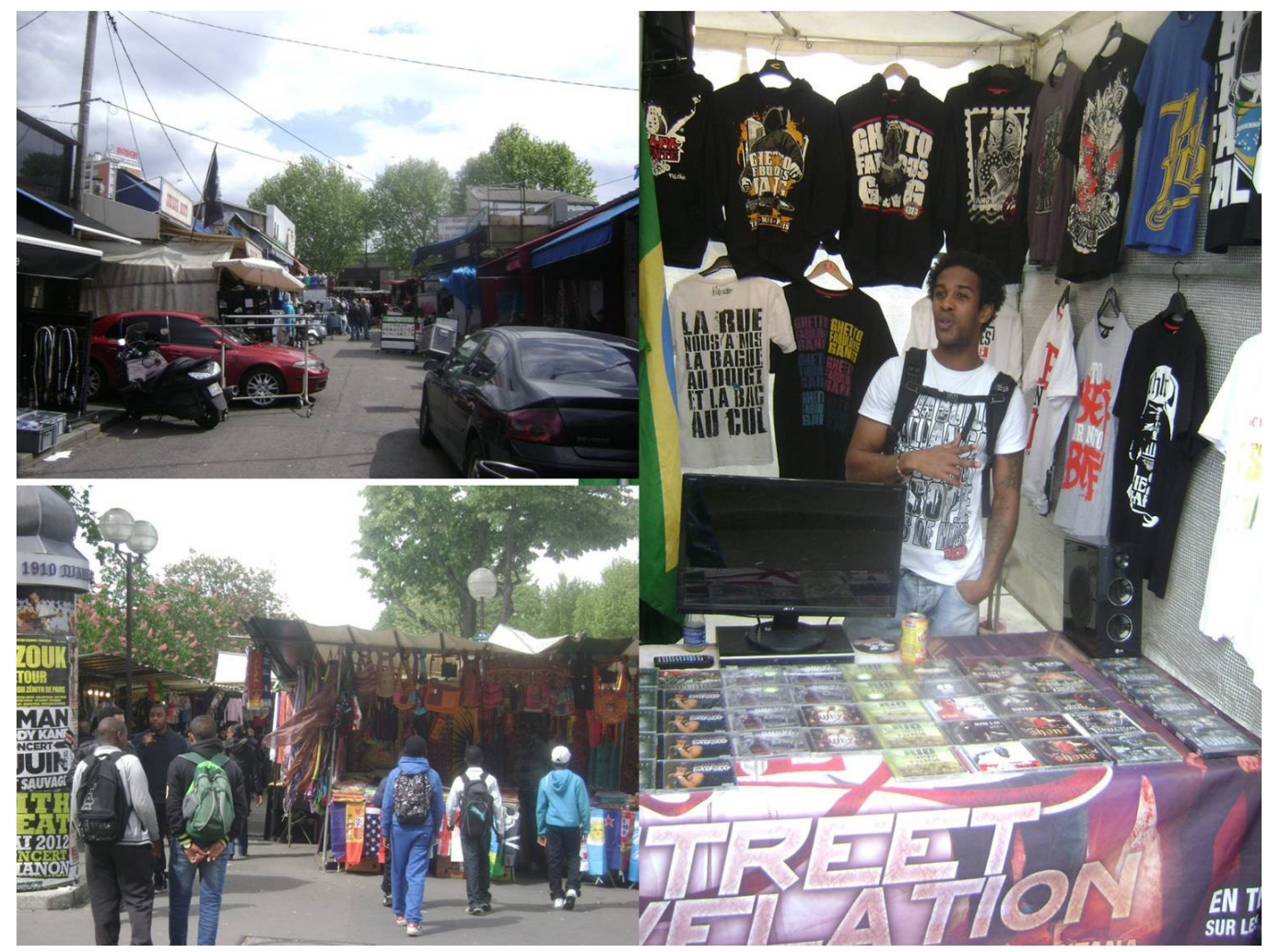

fonte: Cristiano Nunes Alves, mar. 2011. 
Marche-Aux-Puces funciona aos sábados, domingos e segundas-feiras, constituído por barracas ou lojas, onde, por preços populares, pode-se encontrar os mais variados artigos: desde relógios, bolsas, utensilios domésticos, celulares e demais produtos eletrônicos, até artigos ligados ao rap e ao hip-hop, tais quais discos, vestimentas (calças, camisetas, jaquetas ou bonés), DVD etc.

Pelas ruas ao lado do Marché pode-se ainda encontrar diversos utensílios usados, negociados via escambo, vendidos ou comprados: aparelhos de som, discos, rádios, panelas, peças de bicicleta, e inúmeros outros artigos, desinteressantes para a parcela abastada da população parisiense, todavia importantes para os ultramarinos e demais migrantes que por lá circulam. Tais características parecem aproximar-se da dinâmica do circuito inferior da economia nos países do Terceiro Mundo.

Destaca-se o caráter cosmopolita de Clicli, lugar dinamizado por agentes de que representam uma diversidade de culturas: "os cinco continentes estão lá" ressalta um dos rappers em atividade no Marche aux Puces. Ligados ou não ao circuito rap, atuam em Clicli comerciantes - boa parte deles franceses - de inúmeras ascendências: malinesa, haitiana, portuguesa, brasileira, marfinesa, camaronesa, guianesa, guadalupense, senegalesa, congolesa, marroquina, argelina, togolesa etc.

Clicli caracteriza-se por abrigar um vigoroso comércio de artigos ligados ao circuito rap indé, realizado pelos próprios rappers em mais de uma dezena de fixos, sejam lojas ou barracas, estas com aluguel diário no valor de 20 euros, pagos a prefeitura de Saint-Ouen. Como destaca, Mouhada, agente do circuito indé, para Clicli afluem "pequenos empresários oriundos das periferias da região".

Nesse lugar de convergência de agentes periféricos, atuam além de uma série de rappeurs solo, duas familias de rappers, cooperativas da área de produção e difusão do rap: a Ghetto Fabulous Gang, liderada pelo rapper senegalês Alpha 5.20, reunindo em sua maioria rappers descendentes da África Subsaariana e a família Truand la Galère, liderada pelos irmãos de origem argelina Morsay e, reunindo, grosso modo, rappers do Magreb, ambas as famílias trabalhando em conjunto.

Alpha 5.20, pioneiro no rap indé na região de Paris é tido como um exemplo para a maioria dos rappers do circuito: "Antes de Alpha não havia ninguém", esclarece o rapper Zahef. Alpha, chamado de le boss (o chefe) pelos outros rappers iniciou sua carreira em 2001 e atualmente dirige três lojas em Clignancourt. Por sua vez, a Família Truand la Galère produz e comercializa o rap em Clicli desde 2002, atividade concentrada em uma loja, onde pode-se encontrar além de CD e DVD de rap indé, uma série de vestimentas, entre elas camisetas vendidas em média por 20 euros, com mensagens que vão desde o Pan-africanismo até o combate ao racismo.

Os agentes do circuito rap indé, sublinham que ambas estas famílias, tidas como referências, mostraram para a França que é possível obter sucesso financeiro com o rap, investindo no próprio trabalho, sem o apoio de uma gravadora. Além da cooperação entre as famílias observou-se uma cooperação destas, com os rappers que trabalham de modo autônomo nas barracas em Clicli: pulsantes círculos de cooperação se edificam. 
Nessa via, os rappers explicam que Clignancourt, "é a vitrine" o lugar onde os rappers se encontram, e onde ocorre "o contato com os clientes" esclarece o rapper de origem senegalesa Orozco Raricim.

Faz-se necessário lembrar que malgrado a importância de Clignancourt no circuito indé, existem rappers que têm pouca ou nenhuma relação com as atividades ali desenvolvidas. Trata-se de um dos círculos de cooperação, o mais antigo e mais espesso, porém não o único no circuito rap indé.

\section{A produção fonográfica no circuito indé: os estúdios e os selos especiali- zados em rap}

Os estúdios fonográficos ligados ao circuito rap indé se distribuem por toda a região de Paris, ${ }^{6}$ não tendo se observado concentração desses fixos numa determinada área: "em Paris existem estúdios de rap, mas agora existem muitos nas periferias também" atesta um dos produtores musicais entrevistados.

Conhecidos entre os rappers por meio dos nomes de seus produtores, os engenheiros de som, profissionais que na França em geral assumem uma função mais técnica que artística, tais estúdios, espraiaram-se na lle-de-France sobretudo a partir do final dos anos 1990, revelam interlocutores pioneiros do circuito rap. Apurou-se que o custo por hora de gravação nos estúdios localizados nos banlieues gira em torno de 20 euros, ao passo que num estúdio de médio porte localizado em Paris o preço por hora de gravação varia entre 30 e 35 euros. Pode-se assim auferir uma média para a Île-de-France de 25 euros por hora de gravação (Tabela 1).

\section{Tabela 1 - O circuito rap indé na região de Paris: produção fonográfica (custo e tempo de trabalho embutidos - média/2012)}

\begin{tabular}{l|l|l}
\hline etapa da produção & custo e tempo/hora (euros) & $\begin{array}{l}\text { tempo/etapa } \\
\text { (minutos) }\end{array}$ \\
\hline gravação das letras & 25 & 180 \\
\hline mixagem & 25 & 150 \\
\hline masterização & 80 & 60 \\
\hline total por fonograma (faixa) & 130 & 390 \\
\hline
\end{tabular}

fonte: Campo de informação primária.

Somando-se a gravação de vocais sobre uma base musical, procedimento elementar do rap às demais etapas constituintes do registro fonográfico (mixagem e masterização), verifica-se que cada fonograma envolve um custo de 130 euros e a mobilização de 6,5 horas de trabalho.

6 Segundo Calenge (2002), a Île-de-France concentra 38,1\% dos estúdios de ensaio, 30,4\% dos estúdios de gravação, localizados sobretudo na primeira coroa de Paris, "talvez porque eles demandem muito espaço e não se possam se situar no centro da cidade" [peut-être parce qu'ils demandent beaucoup d'espace et n' ont pas besoin de se situer en centre ville] (Calenge, 2002, p. 43). Por outro lado, assevera Calenge (2002), a região abriga 58,6\% das gravadoras da França (sem contar as grandes gravadoras), situadas mormente em Paris, exceção para os selos ligados ao rap, preponderantes em Seine-Saint-Denis (93) e em Hauts-de-Seine (92). 
Nessa via, o custo embutido na produção de um álbum no circuito rap indé, varia entre 1.000 e 10 mil euros, de acordo com o os sistemas técnicos e conhecimentos aplicados. No circuito indé, em média com 2.000 euros pode-se produzir um álbum de boa qualidade, por outro lado, acionando-se os chamados beat makers, especialistas na criação de bases musicais para o rap, uma faixa pode custar em torno de 3.000 euros. Entretanto, decorrência das relações de cooperação entre agentes, corolário da produção no circuito indé, descontos, trocas e gratuidade em serviços podem implicar na redução dos custos de produção.

Informações do rapper Alpha 5.20 dão conta de que a produção de um de seus discos lançado em 2010, o emblemático Scarface D'Afrique, referência no circuito indé, teria custado em torno de 2.000 euros (Tabela 2).

\section{Tabela 2 - O circuito rap indé em Paris: custos envolvidos na produção fonográfica do álbum Scarface D'Afrique - Alpha 5.20 (2010)}

\begin{tabular}{l|l}
\hline etapa da produção & custo (euros) \\
\hline gravação & 600 \\
\hline mixagem & 700 \\
\hline masterização & 700 \\
\hline custo total & 2.000 \\
\hline \multicolumn{2}{c}{ fonte: Campo de informação primária. }
\end{tabular}

Ainda no tocante a produção fonográfica indé, observou-se em especial nas comunas no entorno de Paris o funcionamento de estúdios públicos, com preços em torno de sete euros por hora de gravação, utilizados pelos agentes do circuito. Trata-se de fixos oferecendo serviços de qualidade considerada inferior, em geral devido ao precário conhecimento que os seus técnicos têm em relação aos procedimentos de produção específicos do gênero rap: "eles não entenderam que som eu queria" comentou o rapper de origem guianesa Rheys.

Nessa via, parcela considerável dos rappers afirma preferir trabalhar com produtores conhecedores do rap, ainda que dispondo de sistemas técnicos inferiores. Ora, no circuito indé parece ser mais importante o conhecimento apurado do que o acesso a sistema de alta densidade técnica.

Observa-se assim que no circuito indé, o diferencial de um estúdio resulta do custo benefício taxiado na tríade: localização, sistema técnico e preço, contexto no qual a amarração dá-se pelo conhecimento, por parte da equipe do fixo, principalmente do engenheiro de som, das possibilidades técnicas aplicadas ao rap.

Pensando na importância que o conhecimento sobre o rap, tem para a produção fonográfica no circuito indé, aborda-se a dinâmica em torno de um selo/família/estúdio especializado na música da cultura hip-hop, o coletivo Rott Child-Pièce Grizz.

Criado em 1997 por agentes de origem marroquina e argelina, o selo/família Rott Child possui estúdio próprio, o Pièce Grizz que inicialmente localizado em La Villette (Paris), desde 2005 situa-se em Sevran-Beaudottes, banlieue nordeste, num prédio de HLM (habitação de 
aluguel médio), alternativa para a instalação de estúdios fonográficos utilizados pelas classes menos favorecidas francesas (Touché, 1996). Predomina no Selo Rott Child o rap político, direcionado a preocupação com a periferia mundial: "on rap pour le tiers monde" destaca o rapper de origem marroquina Alid.

As atividades do selo/família/estúdio constituem um coletivo dinamizado por 13 agentes diretos (um diretor, dois técnicos de vídeo, um engenheiro de som, dois cantores de apoio e seis rappers) e 96 clientes, entre assíduos e ocasionais, oriundos de diversos lugares da Île-de-France, e de cidades como Marseille ou Lyon (Tabela 3).

\section{Tabela 3 - O circuito Rap Indé: produção fonográfica Selo/Família Rott Child/Estúdio Pièce Grizz (Sevran-Beaudottes)}

\begin{tabular}{|c|c|c|c|}
\hline \multirow{2}{*}{ articulação (agentes) } & \multicolumn{2}{|c|}{ agentes diretos } & 13 \\
\hline & \multicolumn{2}{|l|}{ clientes } & 96 \\
\hline \multirow{5}{*}{$\begin{array}{l}\text { fixo, sistemas técnicos e } \\
\text { serviços } \\
\text { (custos/euros) }\end{array}$} & \multicolumn{2}{|c|}{ investimento em sistemas técnicos } & 15 mil \\
\hline & \multicolumn{2}{|c|}{ aluguel do fixo (mês) } & 400 \\
\hline & \multirow{2}{*}{ fonogramas } & gravação (faixa) & 60 \\
\hline & & masterização (faixa) & 120 \\
\hline & \multicolumn{2}{|c|}{ elaboração de videoclipe } & $500-800$ \\
\hline
\end{tabular}

fonte: Campo de informação primária.

Mustafá, o diretor do Coletivo informa que, por motivos de segurança, mora no estúdio, abrigo ainda para rappers oriundos de cidades mais longínquas em processo de gravação. Com um investimento de 15 mil euros em sistemas técnicos, criou-se uma estrutura capaz de atender demandas por fonogramas e videoclipes, estes últimos elaborados em média com dois dias de trabalho, por preços que variam de 500 a 3.000 euros, a depender dos recursos materiais e imateriais mobilizados. ${ }^{7}$

Apurou-se que o processo criativo no coletivo, especializado em rap, baseia-se em procedimentos colaborativos, nos quais se observa a troca de ideias entre os agentes envolvidos: os rappers e os produtores, que conjuntamente, esmiúçam o arquivo de bases musicais disponível no estúdio e escrevem ou finalizam as letras dos raps.

Por outro lado, grupos de rap contratados por grandes gravadoras utilizam-se de estúdios de maior porte como o Master Disque Europe (Champs Elysées, Paris), fixo com procedimentos de trabalho mais rígidos, e, que, entre outros, em seu próprio sítio na internet traz indicações de hotéis para os músicos em processo de gravação.

7 Não só a videoclipes se restringe a produção visual dos rappers do circuito indé: entre outros, destacam-se o documentário La Verité sur le Rap Indé (2010), dirigido pelo rapper Sinox, ou ainda o longa-metragem La Vengeance (2011), lançado pelos rappers Morsay e Zahef, da família Truand la Galère. Com uma equipe de cerca de 200 pessoas entre atores, figurinistas e equipe técnica, La Vengeance (2011) teve grande repercussão no país, malgrado o boicote sofrido por abordar incisivamente os temas de racismo e discriminação na França. 


\section{A circulação de informações no circuito rap: os eventos musicais, a di- fusão e a comercialização indé}

$\bigcirc$ circuito rap indé de Paris caracteriza-se pela pequena espessura de eventos musicais que movimenta: mesmo os rappers mais conhecidos afirmam realizarem poucas apresentações ao vivo.

Implicam no caráter residual para os eventos musicais em relação à dinâmica do circuito indé, variáveis como os custos envolvidos em sistemas e procedimentos de segurança, aspectos aliados a uma burocracia especialmente recrudescida para os rappers. Nessa via, Zahef, rapper do selo Truand la Galère, alega: "nós não fazemos muitos shows", pois boa parte dessas apresentações do circuito indé, são proibidas pelo Estado devido ao discurso, tido como subversivo.

Lembra-se que, no caso do circuito rap, o conteúdo político pode se afirmar tanto por meio de um discurso engajado, denunciando o racismo ou a desigualdade socioterritorial, quanto por meio de uma mensagem política baseada em elementos de recusa (Home, 1999), ${ }^{8}$ manifestos, entre outros, em contraposição ao Estado ou na anomia apregoada por alguns grupos.

Daí, o rapper Sinox, lembrar que o poder público, ao considerar a postura revolucionária do rap indé, age para evitar apresentações dessa natureza: "Aqui o rap não é aceito pelo Estado... por que na letra do rap existem muitas coisas que são ditas contra o Estado que considera essa, uma atitude revolucionária... é por isso que eles impedem os shows".

A repressão aos eventos musicais do circuito indé ter-se-ia avolumado, sobretudo a partir de 2005, no contexto das revoltas nas periferias francesas, "as rebeliões do outono" (Giblin, 2005), ocasião na qual uma série de grupos de rap, tais quais Ministère Amer, Lunatic e 113, foram censurados e acusados pelo Estado por apologia ao ódio e à violência contra o poder instituído: "cinco quilômetros de Paris e a mentalidade muda" destaca um dos agentes do circuito rap, pondo em relevo o peculiar cotidiano dos banlieues da metrópole.

Não por acaso, avaliam nossos interlocutores, se tratar de uma ação objetivando calar as vozes periféricas, estratégia conjunta de setores conservadores da sociedade francesa, tais quais os partidos de direita, ou a igreja católica, afirmando-se como agente articulador da censura, Nicolas Sarkozy, primeiramente ministro do interior e depois presidente da república.

Somam-se a esses fatores o controverso papel das produtoras de eventos artísticos, agentes mediadores na organização de concertos, e o fato da legislação francesa ser severa com relação à poluição sonora: em propriedade privada, o excesso de regulamentação praticamente inviabiliza a realização de apresentações musicais, ao passo que em espaços públicos, o resultado de um evento musical sem as devidas autorizações será "polícia, prisão e multa" motivo pelo qual "em Paris não ocorrem apresentações ao ar livre", fato assegurado por um de nossos interlocutores.

Os eventos musicais no circuito indé na região de Paris ocorrem mais comumente (1) no formato de show cases, apresentações menores, para 30 a 100 pessoas, realizadas em bares, associações ou ainda em igrejas. (2) sem bilheteria, motivados por questões éticas, em virtude de datas como o Dia Nacional da Abolição da Escravatura, celebrado na França no dia 10 de maio.

8 Home (1999) propõe recusar os poderes instituídos e a arte como instituição, por meio de ações como a vadiagem, a embriaguez no trabalho, o questionamento de direitos autorais ou a simples negação do espetáculo. 
Por outro lado, no circuito rap ligado às grandes gravadoras, predominam amplos patrocínio e divulgação, seja em lançamentos de discos (Foto 4) ou em eventos musicais em locais de maiores, com ingressos, em média, de 50 euros, sendo 10\% do lucro da bilheteria destinados aos artistas.

\section{Foto 4 - Divulgação massiva no circuito rap das grandes gravadoras, estação de metrô Dupleix, Paris}

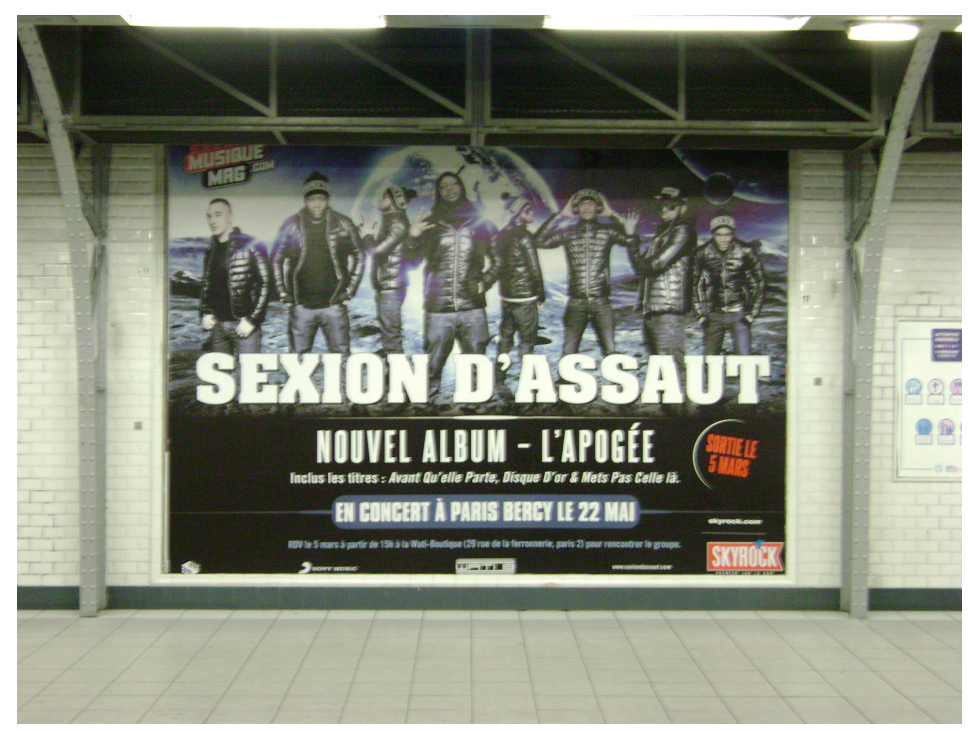

fonte: Cristiano Nunes Alves, set. 2011.

Os eventos musicais e demais ações do rap indé são divulgados em cartazes, de um modo geral fixados em murais de divulgação livre, cartazes, todavia abundantes na área norte de Paris, colocados próximo a lugares de grande fluxo de pessoas, como a estação de metrô de Chatêlet (centro de Paris), a Gare du Nord ou ao longo das vias de acesso ao Boulevard Periphèrique, que circunda a capital.

Para a divulgação da produção no circuito indé, utiliza-se sobremaneira a internet, suas redes sociais e ferramentas audiovisuais, propiciando a articulação do circuito rap alhures, seja por meio do diálogo com aficionados ou via a negociação com diferentes agentes ligados ao rap. Por seu turno, três emissoras FM comerciais difundem o rap em Paris ${ }^{9}$ (Tabela 4), todas mantendo uma relação interesseira com o circuito (1) cobrando o "jabá", a propina do rádio, que pode chegar a 15 mil euros por semana, como condição para veicular determinada música (2) filtrando os artistas de acordo com as conexões que estes têm com as grandes gravadoras (3) promovendo a censura de músicas, caso entre outros, da faixa "Destinée" lançada em 2002 pelo rapper Booba, que teve, como condição para exibição, suprimido um trecho que falava em favor do povo palestino. Vê-se como os mecanismos de difusão massiva da produção fonográfica permanecem condição e resultado de esferas de poder cristalizadas.

9 Central nessa discussão é a lei de 1981 segundo a qual uma série de rádios até então não concessionadas foram liberadas durante o primeiro governo de François Miterrand (1981-1988). Entre elas, a Skyrock e a Génération, que hoje são grandes empresas. Segundo Hammou (2008), o rap é um dos gêneros musicais mais populares entre a juventude francesa, representando 5\% de todas as canções difundidas via rádio na Île-de-France em 2007. Entre 1990-2006, foram vendidos cerca de 35 milhões de álbuns e compilações de rap na França. 


\section{Tabela 4 - A difusão do rap nas rádios FM em Paris: controle da infor- mação e uso corporativo do território}

\begin{tabular}{l|l|l|l}
\hline emissora & localização & $\begin{array}{l}\text { alcance do } \\
\text { sinal }\end{array}$ & $\begin{array}{l}\text { propina para difusão semanal } \\
\text { de fonograma }\end{array}$ \\
\hline Skyrock & Paris, 2 & França & 15 mil euros \\
\hline Générations & Paris, 20 & Île-de-France & 3 a 5 mil euros \\
\hline Energy & Paris & Île-de-France & sem informação \\
\hline
\end{tabular}

fonte: Campo de informação primária.

Desta feita, para divulgar o seu trabalho, os agentes do circuito indé se utilizam das rádios livres, caso, entre outros, das rádios Plurielle (Paris, 19) e Bigop! (banlieue norte): "seja você conhecido ou não, eles te dão a tua chance" sentencia o produtor Mustafá, expondo a postura dessas emissoras com relação à produção do rap indé.

Por sua vez, duplicados em pequenas quantidades, em geral inferiores a mil cópias, os CD e DVD, no circuito indé são vendidos na zona norte de Paris, majoritariamente em Clignancourt e secundariamente em Barbès Rochechouart e na Gare Du Nord, lugares onde o CD é vendido por preços negociáveis que gravitam em torno de 10 euros, com lucro dividido em partes iguais entre o vendedor e o artista. Por outro lado, nos grandes magazines como a Virgin ou a Fnac, um CD vendido pelo preço de 12 euros, terá apenas dois euros revertidos para o artista. Como se pode notar, também quanto à circulação no rap indé, uma série de características suscita similitudes com o circuito inferior da economia urbana nos países do Terceiro Mundo.

Por fim, evidencia-se que os agentes ultramarinos do circuito rap indé comercializam a sua produção também via canais de música digital: Orange, I-tunes, Amazon, Fnac, Deezer, SFR, são algumas das empresas envolvidas no comércio de arquivos digitais vendidos em média por cinco euros. $\bigcirc$ sítio da internet youtube e as web rádios figuram como importantes fontes de receita para os rappers do circuito indé. $\bigcirc$ rateio nesses canais se realiza de acordo com o número de exibições obtido por cada um dos vídeos de rap, alguns dos quais ultrapassando o número de um milhão de acessos.

\section{Considerações finais}

$\bigcirc$ circuito rap indé conflui para a expressão estético-política de grande parte dos agentes ultramarinos da metrópole parisiense, questionadores da discriminação a que são submetidos. Trata-se de um circuito musical associado a vultosas densidades comunicacionais, pois erigido nos lugares, tributário da contiguidade e da troca de experiências, implicando a difusão de um discurso instituinte, a mensagem ultramar, em dissonância com os setores conservadores da sociedade francesa.

Ante a experiência parisiense, defende-se a tese de que, em virtude do adensamento de fluxos informacionais e humanos no mundo contemporâneo, no caso francês, fluxos entre o hexágono e os territórios ultramarinos, além de periferias europeias, como o leste do continente, estaríamos presenciando uma reorganização da metrópole, cujas implicações, embora ainda turvas, parecem consideráveis. 
Assim, poder-se-ia afirmar o funcionamento de um circuito inferior da economia na França, contexto no qual a estabilidade dos pontos luminosos parisienses choca-se com a opacidade de uma espessura ultramarina, feita e refeita em enclaves articulados à vida da urbe (Santos; Silveira, 2001).

Por meio desse circuito rap, fluxos e materialidades se organizam, articulando Paris e seus banlieues em torno da recusa da orquestração espetacular imposta pela indústria cultural. Tendo Clignancourt como ponto de encontro, esses agentes vivem em toda a região de Paris, boa parte produzindo seus fonogramas em estúdios e selos de pequeno porte, fixos especializados em rap ou organizados em coletivos, como as familias. Ao que tudo indica, a maior fonte de renda do circuito rap, caracterizado pela pouca espessura de eventos musicais, dá-se pelo recolhimento de divisas oriundas da execução de vídeos e fonogramas via internet e da venda de artigos ligado ao rap e ao hip-hop.

Uma série de aspectos da dinâmica do circuito rap indé aponta para o modo de operação do circuito inferior da economia nos países do Terceiro Mundo, como o trabalho intensivo, o alto grau de improviso e criatividade, a produção reduzida e matizada, os preços negociáveis e o tímido uso de publicidade, entre outros. Como observado, os agentes do circuito indé constituem densas redes de cooperação e executam tarefas ligadas às diversas etapas de produção e difusão musical.

Aqui, acredita-se haver uma vasta agenda de pesquisa a ser considerada nos estudos geográficos, quiçá temática frontalmente cara ao entendimento dos novos usos do território em curso no período atual.

\section{Referências}

ALVES, C. N. O circuito hip-hop na Região Metropolitana de Campinas: para que o território e a arte digam algo sobre nossas vidas. Monografia (Graduação em Geografia) - Instituto de Geociências, Universidade Estadual de Campinas, Campinas, 2005.

ANDRADE, E. N. O movimento negro juvenil: um estudo de caso sobre os rappers de São Bernardo do Campo. Dissertação (Mestrado em Ensino e Educação Comparada) - Faculdade de Educação, Universidade de São Paulo, São Paulo, 1996.

BÉRU, L. Le rap français, un produit musical postcolonial? Volume!, v. 6, n. 1-2, p. 61-79, 2009.

BETTINELLI, S. Paesaggi di note: Bologna città della Musica. Dottorato (Qualità Ambientale e Sviluppo Economico Regionale) - Università Degli Studi di Bologna, Bologna, Italia, 2007.

BRUNET, R.; DOLLFUS, O. Mondes Nouveaux. Paris: Hachette/Reclus, 1990.

CALENGE, P. Les territoires de l'innovation: les réseaux de l'industrie de la musique en recomposition. Géographie, Économie, Société, Paris, v. 4, n. 1, p. 37-56, 2002.

CALOGIROU, C. Le Florida, lieu musical entre banlieue et centre-ville: l'exemple des rappeurs agenais. Les Annales de La Recherche Urbaine, n. 70, p. 48-57, 1996. 
CARNEY, G. Geography of music: inventory and prospect. Journal of Cultural Geography, v. 10, n. 2, p. 35-48, 1990.

Bluegrass Grows all around: the spatial dimensions of a country music style. Journal of Cultural geography, v. 73, n. 4, p. 34-55, 1974.

CLAIRE, G. Géographie et musique: état des lieux, une proposition de synthèse. Geógraphie et Cultures, n. 59, p. 7-26, 2006.

DUBUS, C. Le rap, entre lieux et réseaux: États-Unis, France, Tanzanie. In: RAIBAUD, Y. (Dir.). Comment la musique vient aux territoires. Bordeaux: MSHA, 2009. p. 141-152.

GIBLIN, B. Dictionnaire des banlieues. Paris: Larousse, 2009.

. Dictionnaire des banlieues. Paris: Larousse, 2005.

GIRONCOURT, G. Un nouveau département à la géographie: la géographie musicale. $L a$ Géographie, Paris, n. 5-6, p. 292-302, 1927.

GOMES, R. L. Território usado e movimento hip-hop: cada canto um rap, cada rap um canto. Dissertação (Mestrado em Geografia) - Instituto de Geociências, Universidade Estadual de Campinas, Campinas, 2012.

GRANGENEUVE, L. L. Quelle musique pour les quartiers? deux équipements culturels controversies. Volume! (En ligne), v. 1, n. 2, p. 5-17, 2002.

GUIBERT, G.; PARENT, E. Introduction: Sonorités du hip-hop. Volume !, v. 3, n. 2, p. 5-16, 2004.

GUILLARD, S. Représenter sa ville: l'ancrage des identités urbaines dans le rap des Twin Cities. Cybergeo: revue européenne de géographie (En ligne), Paris, artigo 608, 2012. Disponível em: <http://cybergeo.revues.org/25357>. Acesso em : 21 fev. 2016.

HARTSHORNE, R. Propósitos e natureza da geografia. São Paulo: Hucitec, 1978.

HAMMOU, K. L'économie du rap français. In: FRANÇOIS, P. et al. La musique: une industrie, des pratiques. Paris: La Documentation Française, 2008. p. 134-152.

HOME, S. Assalto à cultura: utopia, subversão e guerrilha na (anti)arte do século XX. São Paulo: Conrad, 1999.

KEYES, C. L. At the crossroads: Rap music and its African nexus. Etnomusicology, v. 40, p. 222-248, 1996.

LA Vengeance. Direção: Mohamed Mehadji, Youssef Mehadji. Produção: Elodie Antonetti, Mohamed Mehadji. Paris: Truand La Galère, 2011. (126 min).

LA Verité sur le Rap Indé. Direção: Sinox. Produção: Sinox. Paris: Medy Zoo, 2010. (260 min).

LÉVY, J. Le tournant geógraphique: Penser l'espace pour lire le monde. Paris: Mappemonde, 1999.

MOREIRA, R. Da região à rede e ao lugar: a nova realidade e o novo olhar geográfico sobre o mundo. ETC: Espaço, Tempo e Crítica, v. 1, n. 1(3), p. 55-70, 2007. 
PUMA, C. Le rap français. Paris: Hors Collection, 1997.

RAIBAUD, Y. Les fêtes musicales: experiénce de la ville et performativité. Geógraphie et Cultures, p. 87-104, 2006. Disponivel em: <https://halshs.archives-ouvertes.fr/halshs-00333346/>. Acesso em: 8 fev. 2016.

RÉRAT, P. Le rap des steppes: I'articulation entre logiques globales et particularités locales dans le hip-hop mongol. Géographie et cultures, n. 59, p. 43-55, 2006.

ROMAGNAN, J.-M. La musique: un terrain nouveau pour les géographes. Géographie et cultures, n. 36, p. 107-126, 2000.

SANTOS, M.; SILVEIRA, M. L. O Brasil: território e sociedade no início do século XXI. Rio de Janeiro: Record, 2001.

SANTOS, M. Por uma epistemologia existencial. In: ARROYO, M. (Org.). Questões territoriais na América Latina. São Paulo: Clacso, 2006. p. 2-8. A natureza do espaço: técnica e tempo, razão e emoção. São Paulo: Hucitec, 1997. . Técnica, espaço e tempo. São Paulo: Hucitec, 1994.

- O espaço dividido: os dois circuitos da economia urbana dos países subdesenvolvidos. Rio de Janeiro: Francisco Alves, 1979.

SILVEIRA, M. L. Economia política e ordem espacial: circuitos da economia urbana. In: SILVA, C. A. Território e ação social: sentidos da apropriação urbana. Rio de Janeiro: Faperj/Lamparina, 2011. p. 35-51.

STÉBÉ, J.-M. La crise des banlieues. Paris: PUF, 1999.

TOUCHÉ, M. Les lieux de répétition des musiques amplifiées: défaut d'équipement et malentendus sociaux. Les Annales de La Recherche Urbaine, n. 70, p. 58-67, 1996.

ZOBDA-ZEBINA, M. Dancehall aux Antilles, rap en France hexagonale. Volume!, v. 6, n. 1-2, p. $47-58,2009$. 